\title{
Rheological Properties of Five Plant Gums
}

\author{
Quanquan Miao, Huaishi Jiang, Lei Gao, Yujie Cheng, Jiachao Xu, Xiaoting Fu, Xin Gao* \\ College of Food Science and Engineering, Ocean University of China, Qingdao, China \\ Email: *xingao@ouc.edu.cn
}

How to cite this paper: Miao, Q.Q., Jiang, H.S., Gao, L., Cheng, Y.J., Xu, J.C., Fu, X.T. and Gao, X. (2018) Rheological Properties of Five Plant Gums. American Journal of Analytical Chemistry, 9, 210-223. https://doi.org/10.4236/ajac.2018.94017

Received: January 25, 2018

Accepted: April 21, 2018

Published: April 24, 2018

Copyright $\odot 2018$ by authors and Scientific Research Publishing Inc. This work is licensed under the Creative Commons Attribution International License (CC BY 4.0).

http://creativecommons.org/licenses/by/4.0/ (c) (i) Open Access

\begin{abstract}
The rheological properties of five gum solutions (Gum Shiraz, Karaya Gum, Ghatti Gum, Arabic Gum and Gum Tragacanth) have been examined. The five mucilage solutions exhibited non-Newtonian, shear-thinning with thixotropy at higher concentrations $(0.5 \%-1 \%, \mathrm{~m} / \mathrm{v})$. According to the change of viscosity with increasing temperature, all five gums could be defined as three types: gum tragacanth and gum shiraz have a good temperature stability; karaya gum is affected by temperature obviously; the remaining two gums have a general stability. The viscosity of mucilage solutions (Arabic Gum, Ghatti Gum and Karaya Gum) had an apparent dependence on temperature. The parameter $\mathrm{n}$ of Shiraz Gum is the minimum, which means it has the best flow properties. The flow activation energy of karaya gum is $2.683 \mathrm{kcal}$ which is the highest than other gums so that it has a great influence on temperature. The gum solutions' viscosity had different sensitive degree over tested $\mathrm{pH}$ range ( $\mathrm{pH} 2-10)$. Shiraz gum and arabic gum possessed better acid-proof and alkali-proof respectively. The addition of salts $(\mathrm{NaCl}$ and $\mathrm{CaCl}_{2}$ ) led to the reduction of viscosity, which was more sensitive to $\mathrm{Ca}^{2+}$ than to $\mathrm{Na}^{+}$. Both storage modulus G' and loss modulus G” of all five gums had a dependence on temperature and frequency. These results are potentially useful for the application in the field of food processing.
\end{abstract}

\section{Keywords}

Plant Gums, Rheological Properties, Viscosity Behavior, Storage Modulus, Loss Modulus

\section{Introduction}

Plant gum has a complex and highly branched structure with a large number of polysaccharides as well as protein and phenolics [1]. There are many groups that correspond to their functions [2] [3] [4] [5]. The application of plant gums is owing to the water-hold capacity to form a gel structure or thicken the liquid 
and enhance the emulsion stability. The properties using in food have a high dependence on their chemical structure which could be assessed by rheological properties [6]. Some researchers have studied the rheological properties of some plant gums like arabic gum [7] and gum tragacanth [8]. However, there is also no research about the reasons that contribute to these different rheological properties among different plant gum. These studies also lack the systematic research of rheological properties of plant gums such as frequency sweep and the factors influencing its rheological properties. Thus, the rheological properties of five plant gums were studied. According to market share, we selected five plant gums (karaya gum, ghatti gum, shiraz gum, arabic gum and gum tragacanth) to explore the common and specific characteristics between five plant gums. This work is also to make a guidance for these five plant gums (karaya gum, ghatti gum, shiraz gum, arabic gum and gum tragacanth) practical application in food processing and application.

\section{Materials and Methods}

\subsection{Material and Sample Preparation}

The dry powders of five gums were supplied in dried form by Zhengzhou Boyan $\mathrm{CO}$, China. Gums aqueous solutions at concentrations ranging from $0.1 \%$ to $2 \%$ $(\mathrm{m} / \mathrm{v})$ were prepared by dissolving the powder in distilled water. The solutions were agitated gently at $60^{\circ} \mathrm{C}$ for $40 \mathrm{~min}$, and then left to stand overnight to ensure gum hydration. $\mathrm{HCl}$ and $\mathrm{NaOH}(0.1 \mathrm{M})$ were used to adjust the $\mathrm{pH}$ of solutions (1\%). A small amount of $\mathrm{HCl}$ and $\mathrm{NaOH}$ was used in solution to avoid the influence of excessive $\mathrm{Na}^{+}$and $\mathrm{Cl}^{-}$. All other chemicals used were of analytic grade.

\subsection{Rheological Measurements}

All samples were used for rheological measurements and were performed by using a rheometer (MCR101) equipped with a cone plate $(50 \mathrm{~mm}$ diameter, cone angle $2^{\circ}$ ). For these rheological measurements which includes steady shear properties, effects of concentration, temperature, $\mathrm{pH}$ salts on viscosity and dynamic viscoelastic properties.

\subsubsection{Steady Shear Properties}

For steady tests, samples were measured at a rate ranging from 0.01 to $100 \mathrm{~s}^{-1}$ at $25^{\circ} \mathrm{C}$. The flow behavior could be analyzed by using the Power-law model (Equation (1))

$$
\tau=k \gamma^{n}
$$

where $\tau$ the shear stress $(\mathrm{Pa}), k$ is the consistency coefficient (Pa.s n), $\gamma$ is the shear rate $\left(\mathrm{s}^{-1}\right)$, and $\mathrm{n}$ is the flow behavior index. This parameter provides an indication of the conformation of polysaccharides [9] [10] [11].

The non-Newtonian fluids are classified into three different types according to the value of $n: n<1$ shear-thinning fluids, $\mathrm{n}=1$ Newtonian fluids, $\mathrm{n}>1$ 
shear-thickening fluids.

\subsubsection{Effect of Concentration on Viscosity}

Five solution samples were used for rheological measurements to approach the effect of concentration on viscosity in the concentration of $0.1 \%, 0.2 \%, 0.5 \%, 1 \%$, $2 \%(\mathrm{~m} / \mathrm{v})$ respectively.

\subsubsection{Effect of Temperature on Viscosity}

The effect of temperature on viscosity was characterized using the rheometer. The heating temperature was from $20^{\circ} \mathrm{C}$ to $90^{\circ} \mathrm{C}$, with heating rates of $5^{\circ} \mathrm{C} / \mathrm{min}$. It is described by the Arrhenius equation (Equation (2)):

$$
\eta=A \exp (E a / R T)
$$

where $\eta$ is the viscosity ( $P a s$ ); $A$ is the proportionality constant; $E a$ is activation energy $(\mathrm{J} / \mathrm{mol}) ; R$ is gas constant $\left(8.314 \mathrm{~J} / \mathrm{mol}^{\star} \mathrm{K}\right)$; and $T$ is temperature $(\mathrm{K})$.

\subsubsection{Effect of $\mathrm{pH}$ on Viscosity}

The $\mathrm{pH}$ value of sample solutions were adjusted to $2,4,6,8,10,12$ using $0.1 \mathrm{M}$ $\mathrm{HCl}$ and $\mathrm{NaOH}$ and the viscosity was tested at $25^{\circ} \mathrm{C}$.

\subsubsection{Effect of Salt on Viscosity}

The effects of $\mathrm{NaCl}$ and $\mathrm{CaCl}_{2}$ on viscosity were investigated by rheometer. Their concentrations ranged from 0 to $30 \mathrm{mg} / \mathrm{ml}$ and the viscosity was tested at $25^{\circ} \mathrm{C}$.

\subsection{Dynamic Rheological Experiment}

Five solution samples (1\%) were prepared by dissolving the powder in distilled water. The solutions were agitated gently at $60^{\circ} \mathrm{C}$ for $40 \mathrm{~min}$, and then left to stand overnight to ensure gum hydration. All dynamic rheological experiments were tested in the liner viscoelastic range.

\subsubsection{Temperature Sweep}

Temperature sweep tests between $20^{\circ} \mathrm{Cand} 90^{\circ} \mathrm{C}$ were carried out at a frequency of $4 \mathrm{~Hz}$ and $1 \%$ strain (in the linear viscoelastic range attained by strain sweep test) to determine the change of storage modulus (G'), loss modulus(G') and loss tangent $(\tan \delta)$.

\subsubsection{Frequency Sweep}

Frequency sweep tests were performed in the frequency range of $1-10 \mathrm{~Hz}$ at $1 \%$ strain and $25^{\circ} \mathrm{C}$ to determined G', G” and $\tan \delta$.

\subsubsection{Time Sweep}

Time sweep was carried out from 0 to $2000 \mathrm{~s}$ to study the complex modulus changes.

\subsection{Statistical Analysis}

Statistical analysis was carried out using Origin 8.0 by applying linear and non-linear regression methods. All the experiments were performed on triplicate 
samples and the results were presented as the means \pm SD. Differences between means $(\mathrm{p}<0.05)$ were conducted by one way ANOVA using SPSS 19.0.

\section{Results and Discussion}

\subsection{Steady Shear Properties}

Figure 1 shows the plot of variation of apparent viscosity for five gum solution samples. There is a decrease in viscosity with the shear rate increases, which means that all samples have shear-thinning properties. Gum tragacanth shows a different viscosity flow behavior with other gums. The remaining four kinds of gum, Karaya Gum sample shows the highest viscosity followed by Arabic Gum and Ghatti Gum and Gum Shiraz shows the lowest apparent viscosity among the tested shear rate range. The shear-shinning nature is due to the change in molecular network, which caused by the alignment of polusaccharide chains in the direction of shear and the disruption of molecular tanglements under the application of shear [12].

The molecular weight and the ability of combination of water molecular are the mainly reasons for the observed different shear properties [13]. In addition to structural reasons, the gum tragacanth has the effect of intermolecular electric field force [14]. So, the gum tragacanth showed a different flow curve.

As shown in Figure 2, the flow behavior can be described by Power Law Model. The rheological parameters for viscosity were displayed in Table 1 . The values of flow behavior index (n) are less than 1, which means the flow behavior of five plant gum solutions are non-Newtonian fluid. The $\mathrm{K}$ and $\mathrm{n}$ value respectively

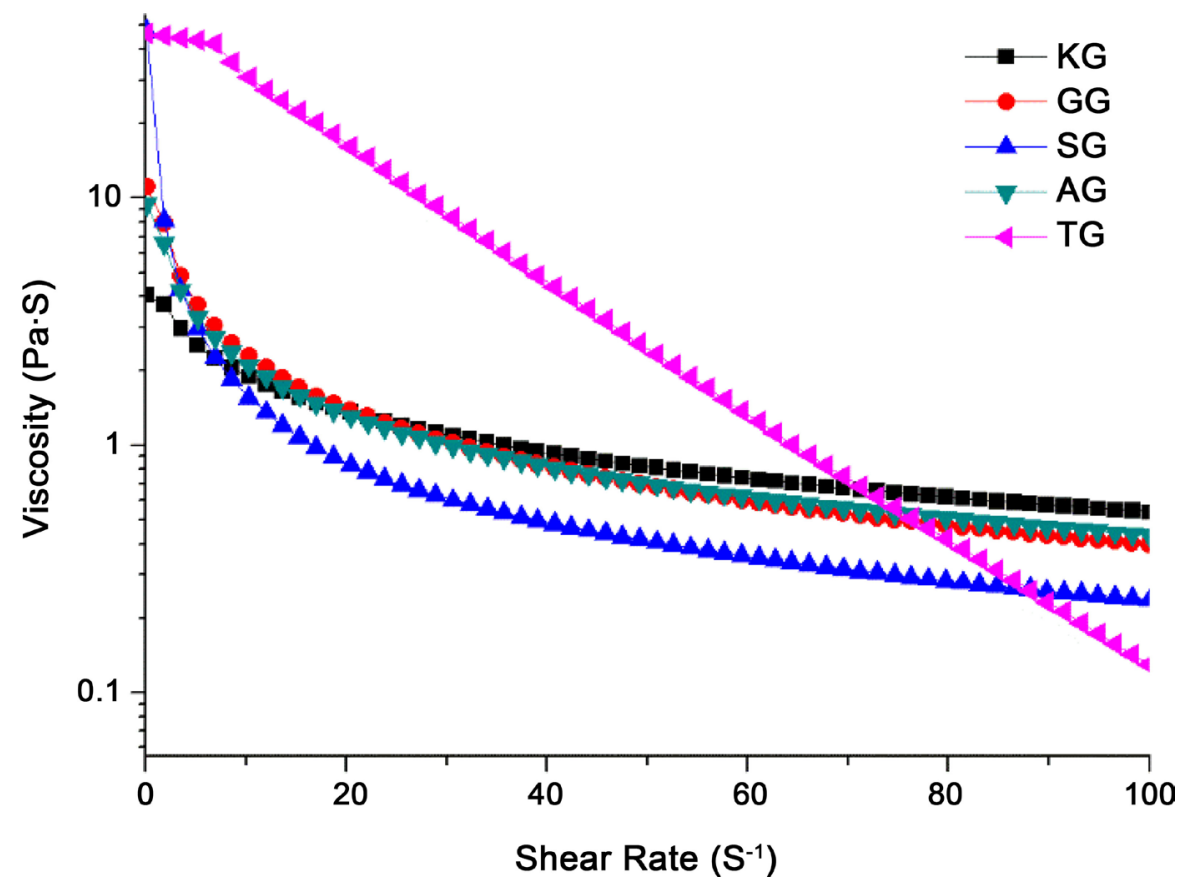

Figure 1. Apparent viscosity flow behavior for five gum solutions versus shear rate ramps $\left(1 \% \mathrm{~m} / \mathrm{v}, 25^{\circ} \mathrm{C}\right)$ (KG-Karaya Gum, GG-Ghatti Gum, SG-Gum Shiraz, AG-Arabic Gum, TG-Gum tragacanth). 


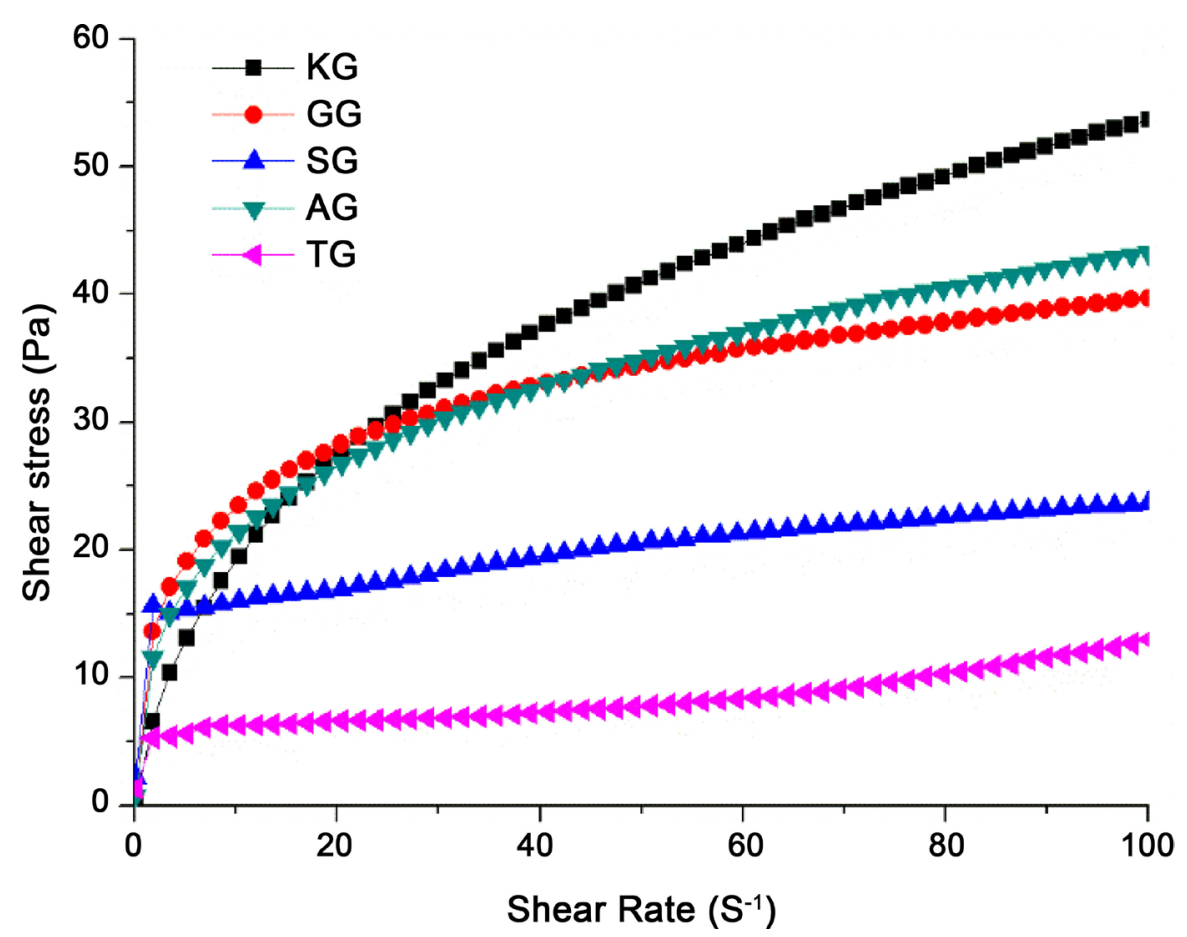

Figure 2. Shear stress flow behavior for five gum solutions versus shear rate ramps.

Table 1. Rheological constants for powder law model.

\begin{tabular}{cccc}
\hline \multirow{2}{*}{ Sample } & \multicolumn{3}{c}{ Power Law } \\
\cline { 2 - 4 } & $\mathrm{k}$ & $\mathrm{n}$ & $\mathrm{R}^{2}$ \\
\hline Gum karaya & 7.296 & 0.437 & 0.9958 \\
Ghatti gum & 13.217 & 0.243 & 0.9795 \\
Gum shiraz & 10.354 & 0.177 & 0.9230 \\
Arabic gum & 10.212 & 0.315 & 0.9958 \\
Gum tragacanth & 7.013 & 0.123 & 0.9667 \\
\hline
\end{tabular}

reflect the viscosity and shear-shinning properties. The ghatti gum solution has the highest $\mathrm{K}$ value indicates it has the highest viscosity. The gum karaya has the highest $\mathrm{n}$ value means the greater shear-thinning properties and the high value of $\mathrm{n}$ tend to feel slimy in the mouth.

\subsection{The Effects of Concentration, Temperature, $\mathrm{Ph}$, Salt on Apparent Viscosity}

An increase in concentration with the increase of apparent viscosity was shown in Figure 3. As can be seen from Figure 3, all five plant gums exhibited great concentration-dependence behavior. Ghatti gum and arabic gum showed Newtonian behavior at low concentration and there is a pseudoplasticity of shear-thinning with the higher concentration. The remain three kinds of gum were the non-Newtonian fluids at a low concentration which means these three samples could form hydrogen bond force and entanglement between molecules 


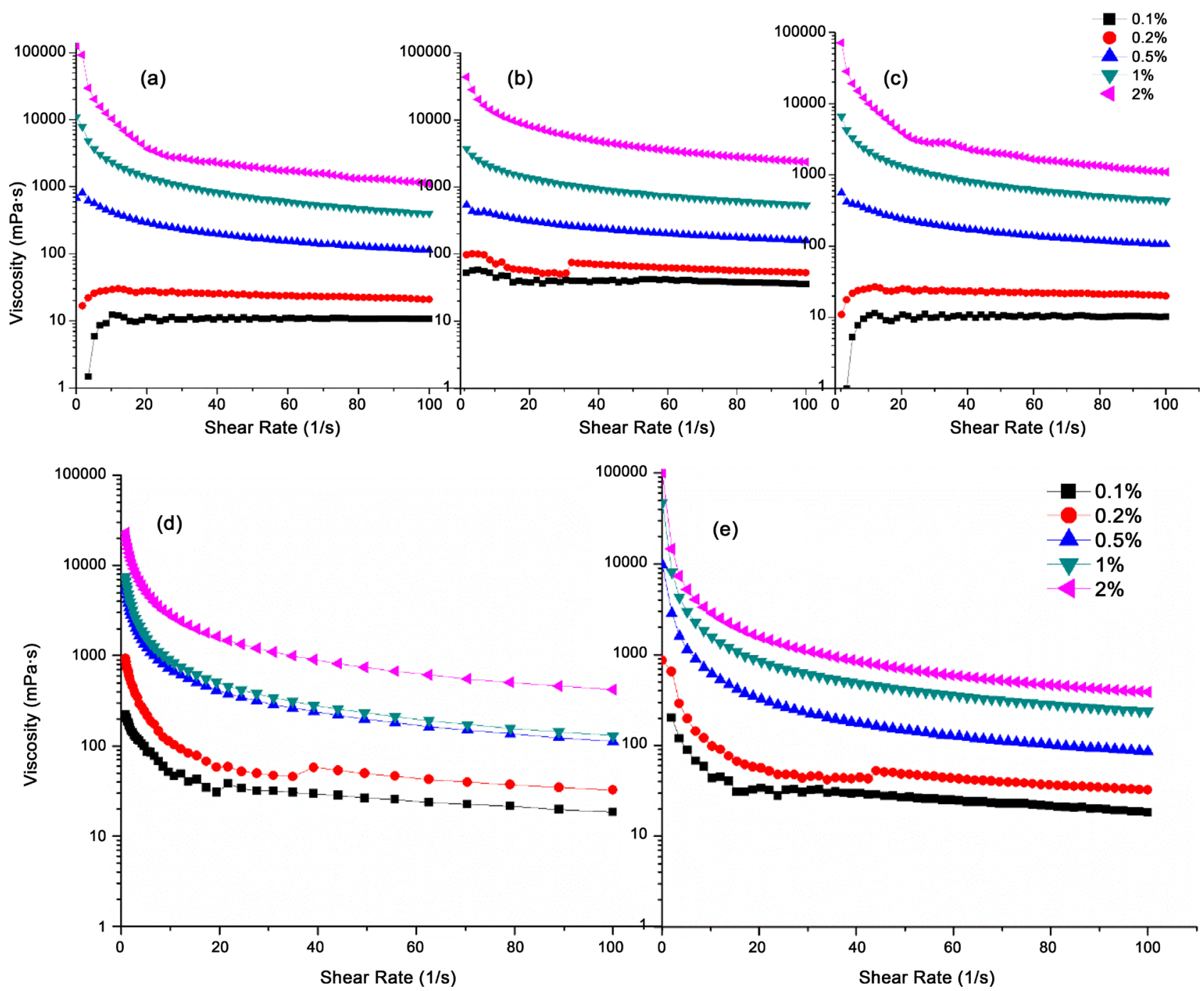

Figure 3. Effect of different concentration on apparent viscosity of five plant gums ((a) ghatti gum; (b) gum karaya; (c) arabic gum; (d) gum shiraz; (e) gum tragatanth.

at a low concentration. The Graessley's entanglement theory explains this behavior as the decrease in entanglement density upon induced flow, which depends on temperature and ploymer concentration [15].

The relationship between viscosity and temperature of five plant gums is shown in Figure 4. From the Figure 4, it clearly shows that temperature has a various influence on apparent viscosity. Based on the effect of temperature on viscosity, five plant gums could be divided into three types. The viscosity of shiraz gum and gum tragacanth has little changes as the temperature increases and have a good thermal stability. Compared with shiraz gum and gum tragacanth, the viscosity of karaya gum, ghatti gum and arabic gum decreased with the increase of temperature from $0^{\circ} \mathrm{C}-90^{\circ} \mathrm{C}$, indicating the temperature dependence of these three gums. This may be attributed to molecular thermal motion causing by the increase of temperature, which enlarged the intermolecular distance and weakened the network structure. The effect of temperature on viscosity 
could be described by arrhenius model and the parameter of Ea and $\mathrm{R}^{2}$ are showed in Table 2. The parameters of five gums' activation energy (Ea) were different, in which a higher Ea means a more rapid change in viscosity [16]. As can be seen in Table 2, karaya gum has the highest value of activation energy, which means it was most sensitive to the change of temperature. The results suggest that temperature control is vital for karaya gum in food processing.

As shown in Figure 5, the effect of $\mathrm{pH}$ on the viscosity was investigated. From the figure, the apparent viscosity was effected with the change of $\mathrm{pH}$. Shiraz gum has a better alkali resistance. The apparent viscosity of arabic gum has a little change in the acidic range due to the nature of acidic polysaccharide. Gum tragacanth showed the lowest viscosity at $\mathrm{pH} 8$, then increase gradually and the apparent viscosity of gum tragacanth marked decline at a $\mathrm{pH}$ range of $2-8$. This can attribute to the process of recovering the molecule after melting. There is a growing trend for the apparent viscosity of karaya gum and ghatti gum in an acidic environment. With the increase of $\mathrm{H}+$ in solution, the polymer was dissociated gradually, resulting in weakening in molecular force and the decrease of apparent viscosity.

The effect of salt on viscosity is shown in Figure 6. The addition of salts led to a decrease in viscosity and the effects were more pronounced with increasing salt concentration. Comparatively, the viscosity of solutions is more sensitive to

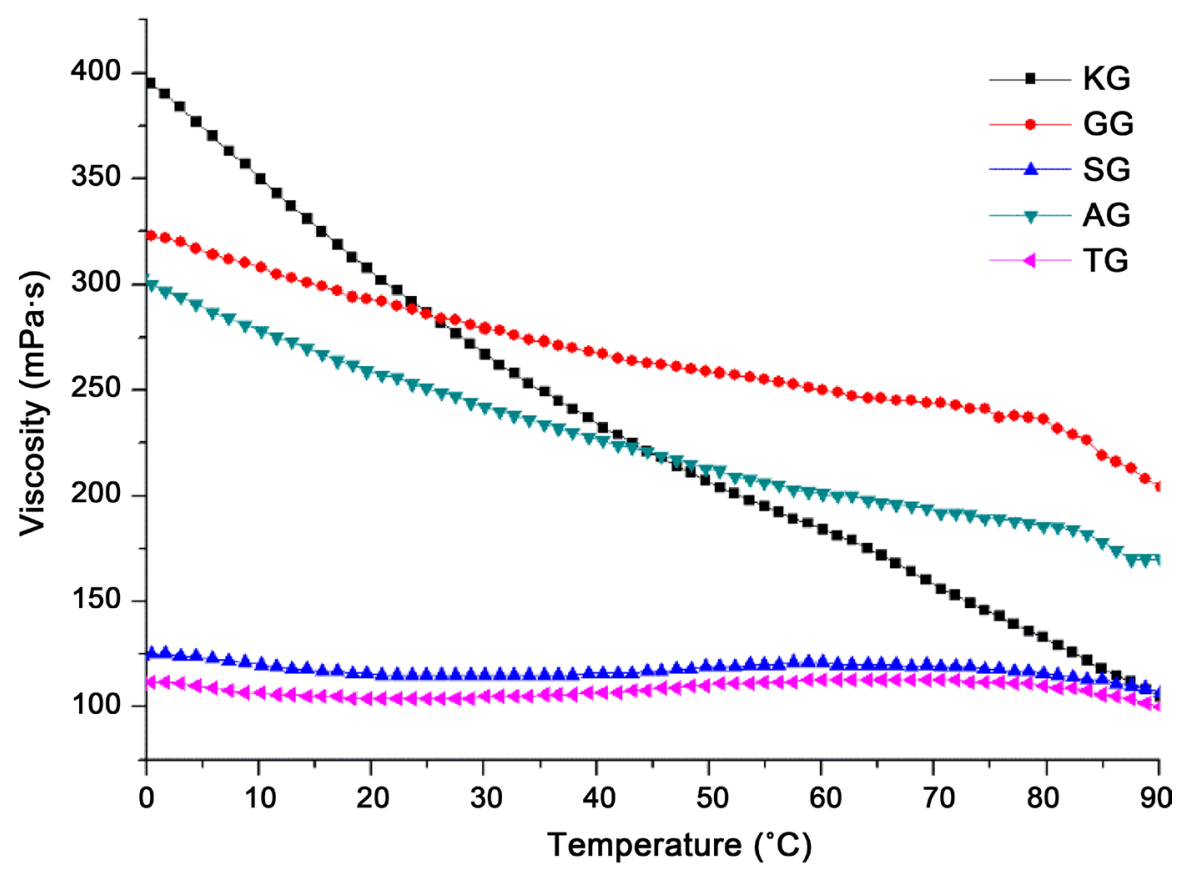

Figure 4. Effect of temperature on apparent viscosity of five plant gums.

Table 2. Arrehenius equation parameters of apparent viscosity.

\begin{tabular}{cccccc}
\hline & Karaya gum & Ghatti gum & Gum shiraz & Arabic gum & Tragacanth gum \\
\hline $\mathrm{Ea}(\mathrm{kcal})$ & 2.683 & 0.831 & 0.503 & 1.038 & 0.605 \\
$\mathrm{R}^{2}$ & 0.970 & 0.971 & 0.962 & 0.997 & 0.955 \\
\hline
\end{tabular}




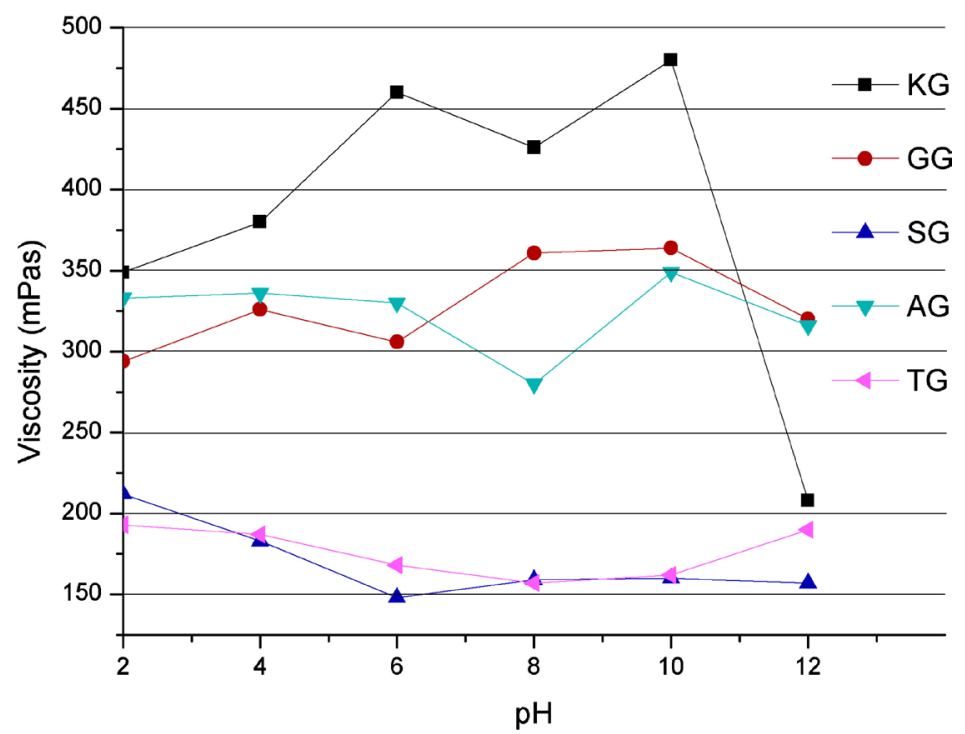

Figure 5. Effect of $\mathrm{pH}$ on apparent viscosity of five plant gums.
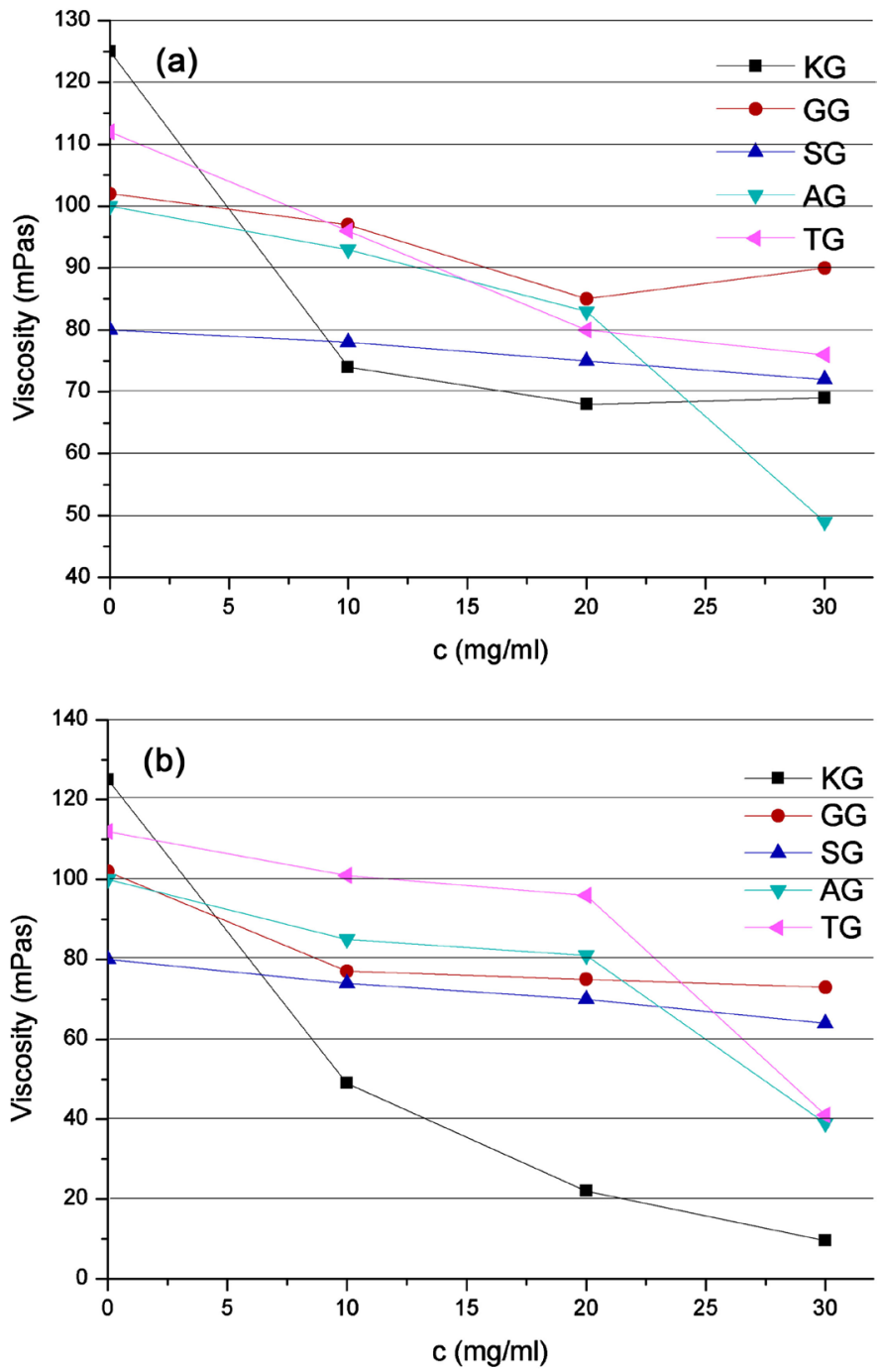

Figure 6. Effect of Salt on apparent viscosity of five plant gums. 
$\mathrm{CaCl}_{2}$ than to $\mathrm{NaCl}$. These data also suggest that these five gums might be a negatively charged polyelectrolyte in solution. The addition of positive ions can reduce the repulsion forces of negatively charged polyelectrolyte molecules and molecular expansion, and hence produces a rapid reduction of viscosity [17]. Divalent salt $\mathrm{CaCl}_{2}$ has stronger capability to reduce the repulsion and molecular expansion than monovalent salt $\mathrm{NaCl}$ and it provided a significant effect on viscosity.

\subsection{Dynamic Measurement Analysis}

We determined $1 \%$ strain and $4 \mathrm{~Hz}$ to test dynamic viscoelastic properties through stress sweep. All dynamic viscoelastic properties are tested in the linear viscoelastic range which the complex modulus $\left(\mathrm{G}^{*}\right)$ keeps steady with the oscillation changes [18]. Figure 7 shows the variation in G'(storage modulus) and G”(loss modulus) with the increase of temperature. As can be observed, all of G' and $G$ " show a downward trend in the range of temperature $\left(20^{\circ} \mathrm{C}-90^{\circ} \mathrm{C}\right)$. The storage modulus of ghatti gum, shira gum, arabic gum and gum tragacanth always greater than loss modulus according to the value of $\tan \delta$. All the value of $\tan \delta$ is below 1 , which indicates that mucilage solutions will show mainly the elastic properties and behave as a solid. However, the G' value of karaya gum became zero after $60^{\circ} \mathrm{C}$ and G" always superior to G' which means that the mucilage solutions show the viscous properties.

The storage modulus and loss modulus of dynamic tests for $1 \%$ gum solutions are shown in Figure 8. The observation suggests that five gums (ghatti gum, shiraz gum, arabic gum and gum tragacanth) will exhibit elastic properties according to the value of storage modulus G' is higher than loss storage G" [19]. the G' of shiraz gum and gum tragacanth tend to increase and then decrease at the range of $1-10 \mathrm{~Hz}$, which indicates that SG and TG have a mutative in viscosity properties over the entire frequency range. It has a different effect on mucilage solutions of karaya gum. The loss modulus G” is higher than storage modulus G' at a low frequency, then a cross over appears at $3 \mathrm{~Hz}$ and $\mathrm{G}^{\prime}$ become higher than $G$ ' in the following frequency range, mucilage solution of karaya gum will show mainly elastic properties at a lower frequency.

The variation in storage modulus G' and loss modulus G" are represented in Figure 9. It is shown that the G' and G" has no change with the increase of time, which means all five plant gums are not time-dependent fluids. The behaviors are consistent with the results of steady-state rheology analysis.

\section{Conclusions}

The results of this study investigated the rheological properties of five plant gums. Rheological results showed that all samples have the non-Newtonian shear-thinning properties at a high concentration, which could be described by the power law model. Mucilage solutions of all five gums were found obviously concentration and temperature dependent. They could be divided into three 

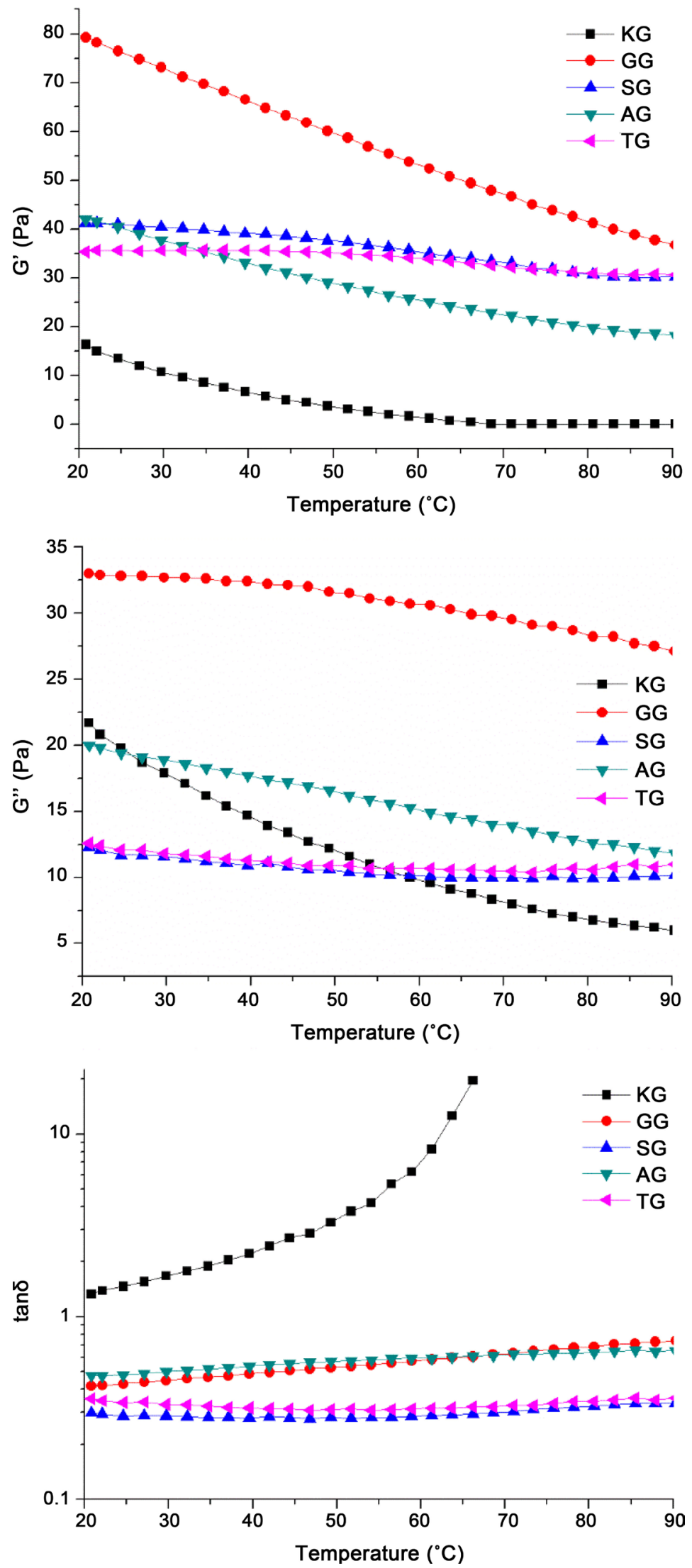

Figure 7. Temperature sweep (G', G', $\tan \delta$ ) of five plant gums. 

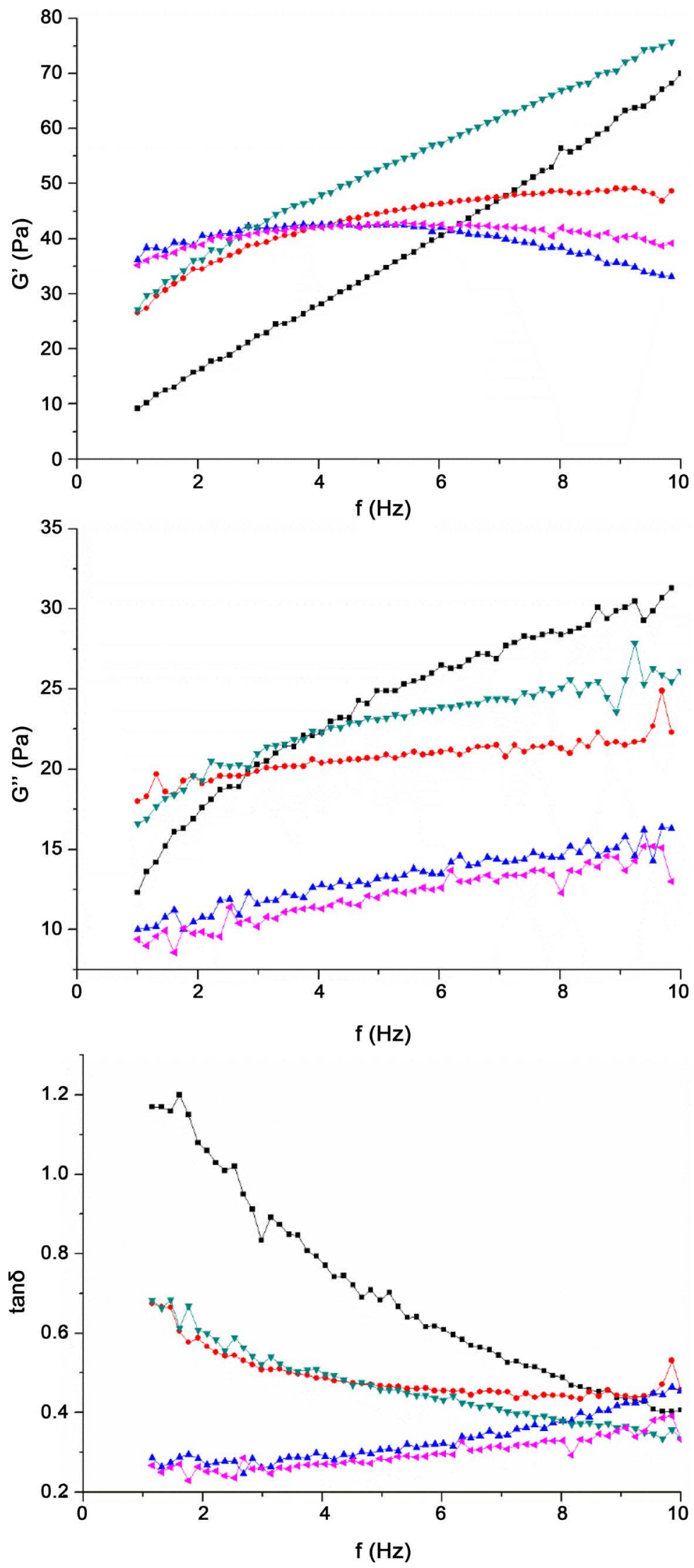

Figure 8. Frequency sweep (G', G”, $\tan \delta$ ) of five plant gums. 

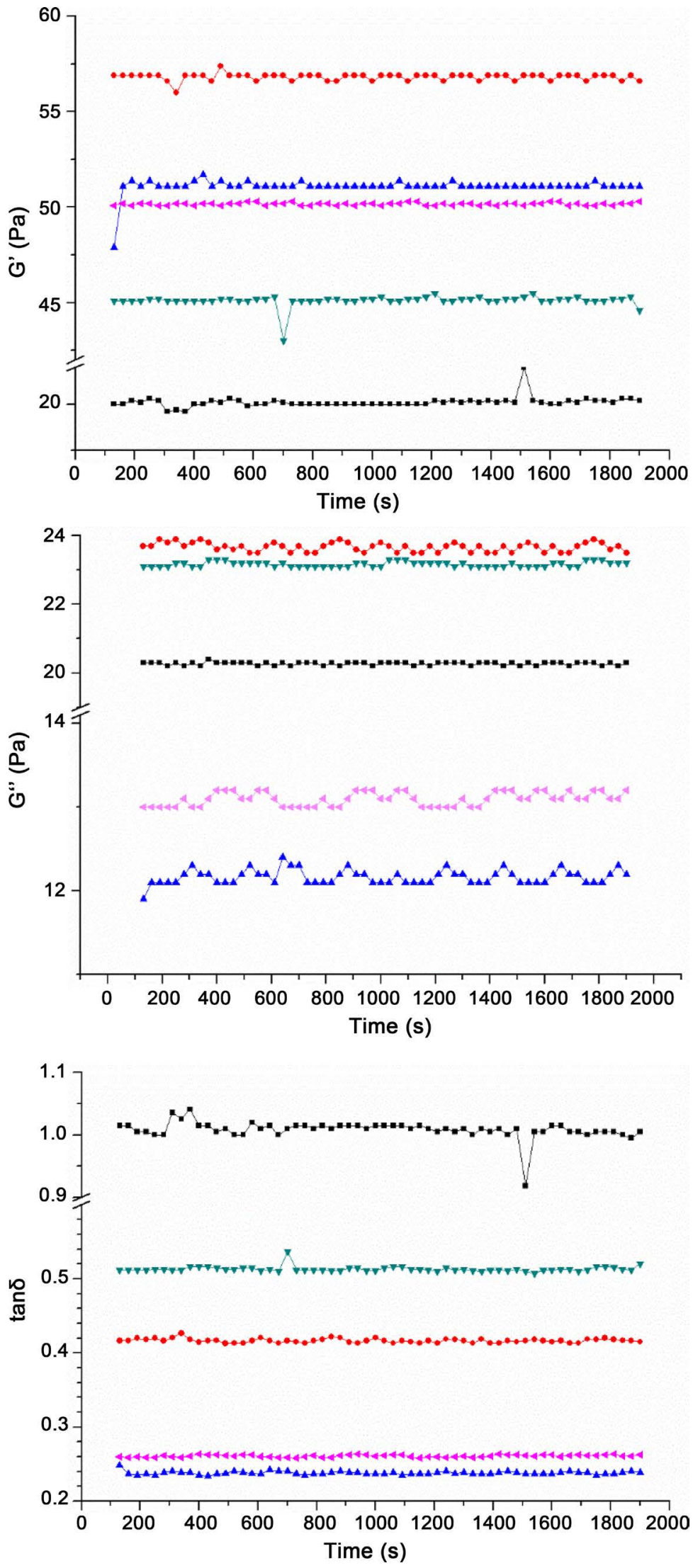

Figure 9. Time dependent behavior of five plant gums. 
types according to the change of temperature. All samples possessed different sensitive degree over the tested $\mathrm{pH}$ range and Shiraz gum and Arabic gum had acid-proof and alkali-proof advantages. A dependent of slats was also found, as the concentration of salt increased, and the viscosity decreased obviously.

The dynamic viscoelastic properties were studied in the linear viscosity region. Both elastic modulus G' and loss modulus G" had a dependence on frequency and temperature. The storage modulus G' of ghatti gum, shiraz gum, arabic gum and tragacanth gum are always superior to loss storage G", which means the elastic property has a better response to the temperature than the viscosity property. The karaya gum solution became a viscous fluid at a higher temperature. The $\tan \delta$ of four gums is always lower than 1 , which indicates that mucilage solutions will show an elastic property and a trendy to form a gel. For karaya gum, the loss modulus G" is higher than storage modulus G' at a low frequency, and then a cross-over appears at $3 \mathrm{~Hz}$. Shiraz gum and gum tragacanth tend to increase and then decrease at the range of $1-10 \mathrm{~Hz}$. The storage modulus G' is higher than loss modulus G" except the karaya gum. All five mucilage solutions are not time-dependent fluids.

\section{Acknowledgements}

This study was supported by the project sponsored by National Natural Science Foundation of China (No. 31571865).

\section{References}

[1] Verbeken, D., Dierckx, S. and Dewettinck, K. (2003) Exudate Gums: Occurrence, Production, and Applications. Applied Microbiology and Biotechnology, 63, 10-21. https://doi.org/10.1007/s00253-003-1354-Z

[2] Delgobo, C.L., Gorin, P.A.J., Tischer, C.A. and Iacomini, M. (1999) The Free Reducing Oligosaccharides of Angico Branco (Anadenanthera colubrina) Gum Exudate: An Aid for Structural Assignments in the Heteropolysaccharide. Carbohydrate Research, 320, 167-175. https://doi.org/10.1016/S0008-6215(99)00159-7

[3] Maurer-Menestrina, J., Sassaki, G.L., Simas, F.F., Gorin, P.A.J. and Jacomini, M. (2003) Structure of a Highly Substituted b-Xylan of the Gum Exudate of the Palm Livistona chinensis (Chinese Fan). Carbohydrate Research, 338, 1843-1850. https://doi.org/10.1016/S0008-6215(03)00276-3

[4] Delgobo, C.L., Gorin, P.A.J., Jones, C. and Iacomini, M. (1998) Gum Heteropolysaccharide and Free Reducing Mono- and Oligosaccharides of Anadenanthera colubrina. Phytochemistry, 47, 1207-1214. https://doi.org/10.1016/S0031-9422(97)00776-0

[5] Jones, J.K.N. and Smith, F. (1949) Plant Gums and Mucilages. In: Pigman, W.W. and Wolfrom, M.L., Eds., Advances in Carbohydrate Chemistry, Vol. 4, Academic Press, New York, 243-291. https://doi.org/10.1016/S0096-5332(08)60051-X

[6] Rinaudo, M. (2001). Relation between the Molecular Structure of Some Polysaccharides and Original Properties in Sol and Gel States. Food Hydrocolloids, 15, 433-440. https://doi.org/10.1016/S0268-005X(01)00041-8

[7] Li, X.B., Fang, Y.P., Al-Assaf, S., Phillips, G.O., Nishinari, K. and Zhang, H.B. (2009) Rheological Study of Gum Arabic Solutions: Interpretation Based on Mole- 
cular Self-Association. Food Hydrocolloids, 23, 2394-2402.

https://doi.org/10.1016/j.foodhyd.2009.06.018

[8] Chauhan, G., Pillai, P. and Ojha, K. (2017) Rheological Studies of Gum Tragacanth as a Prospective Candidate for Hydraulic Fracturing. Materials Today, 4, 9413-9417. https://doi.org/10.1016/j.matpr.2017.06.195

[9] Higiro, J., Herald, T., Alavi, S. and Bean, S. (2007) Rheological Study of Xanthan and Locust Bean Gum Interaction in Dilute Solution: Effect of Salt. Food Research International, 40, 435-447. https://doi.org/10.1016/j.foodres.2006.02.002

[10] Lai, L., Tung, J. and Lin, P. (2000) Solution Properties of Hsian-Tsao (Mesona Procumbens Hemsl) Leaf Gum. Food Hydrocolloids, 14, 287-294. https://doi.org/10.1016/S0268-005X(99)00069-7

[11] Razmkhah, S., Razavi, S.M.A. and Mohammadifar, M.A. (2017) Dilute Solution, Flow Behavior Thixotropy and Viscoelastic Characterization of Cress Seed (Lepidium sativum) Gum Fractions. Food Hydrocolloids, 63, 404-413. https://doi.org/10.1016/j.foodhyd.2016.09.030

[12] Rao, M.A. and Cooley, H.J. (1984) Determination of Effective Shear Rates in Rotational Viscometers with Complex Geometries. Journal of Texture Studies, 15, 327-335. https://doi.org/10.1111/j.1745-4603.1984.tb00390.x

[13] Bourbon, A.I., Pinheiro, A.C., Ribeiro, C., Miranda, C., Maia, J.M., Teixeira, J.A., et al. (2010) Characterization of Galactomannans Extracted from Seeds of Gleditsia Triacanthos and Sophora Japonica through Shear and Extensional Rheology: Comparison with Guar Gum and Locust Bean Gum. Food Hydrocolloids, 24, 184-192. https://doi.org/10.1016/j.foodhyd.2009.09.004

[14] Wang, S., He, L., Guo, J., Zhao, J. and Tang, H. (2015) Intrinsic Viscosity and Rheological Properties of Natural and Substituted Guar Gums in Sea Water. International Journal of Biological Macromolecules, 76, 262-268. https://doi.org/10.1016/j.ijbiomac.2015.03.002

[15] Medina-Torres, L., Fuente, B.D.L., Torrestiana-Sanchez, B. and Katthain, R. (2000) Rheological Properties of the Mucilage Gum (Opuntia Ficus Indica). Food Hydrocolloids, 14, 417-424. https://doi.org/10.1016/S0268-005X(00)00015-1

[16] Al Assaf, S., Amar, V. and Phillips, G.O. (2008) Characterisation of Gum Ghatti and Comparison with Gum Arabic. In: Williams, P.A. and Phillips, G.O., Eds., Gums and Stabilisers for the Food Industry, Vol. 14, p. 11.

[17] Liu, D.H. and Gu, W.-Y. (2006) Rheological Properties of Artemis Sphaerocephala Krasch Gum. Food Science, 27, 76-80.

[18] Vinod, V.T., Sashidhar, R.B., Sarma, V.U. and Vijaya Saradhi, U.V. (2008) Compositional Analysis and Rheological Properties of Gum Kondagogu (Cochlospermum gossypium): A Tree Gum from India. Journal of Agricultural \& Food Chemistry, 56, 2199. https://doi.org/10.1021/jf072766p

[19] Richardson, R.K. and Ross-Murphy, S.B. (1987) Non-Linear Viscoelasticity of Polysaccharide Solutions. 1: Guar Galactomannan Solutions. International Journal of Biological Macromolecules, 9, 250-256.

https://doi.org/10.1016/0141-8130(87)90062-6 